Art in an exhibition that ran from 20 October 2016 to 5 February 2017, entitled Dreamlands: Immersive Cinema and Art, 1905-2016.

Given such an array of disciplines, mediums, and venues, it is not surprising that the program aligns itself not with a single body of knowledge but with a shared ethos of teambased improvisation, emphasizing "the relationship between digital methodologies and humanities scholarship"; "collaboration between traditionally disparate disciplines such as Computer Science, Literature, and the Arts"; and "the role of experimentation, often associated with the sciences and the arts, in humanities research." Students enrolled in this concentration have the "option of adding a practice-rich component to their Senior Project" ("About"; Experimental Humanities, eh.bard.edu/about/). That "practice-rich" component seems to have galvanized many students, turning them into experts in their self-chosen and self-directed areas of research. Senior projects growing out of such self-directedness include "Police Brutality on Camera," "Computing Language and Thinking," "Twitterature," "Branching Boogaloo: Botanical Adventures in Multi-mediated Morphologies," and "Game and Train: A Targeted Game-Based Mobile Intervention for the Treatment of Incarcerated Psychopathic Offenders."

The jury is still out on this young program at Bard, as it is on Public Books and the Kelly Writers House. Together, though, these three bear witness to the vitality and variety of the "experimental," making a team-inspired, practice-rich humanities the animating core of a twenty-first-century education.

Wai Chee Dimock Yale University

\section{Measuring Success in the Humanities}

To THE EDITOR:

Gonzalo Aguilar and I were happy to see Wai Chee Dimock's editor's column "Experi- mental Humanities" (vol. 132, no. 2, Mar. 2017, pp. 241-49). Like her, many of us are reaching for a "refresh" button for our profession, which has, in some dimensions, gone stale. The understandable zeal with which humanists defend against practical and measurable criteria has, over the past few generations, isolated us so effectively that we may have blunted the capacity of art interpretation to interrupt conventional thinking. A noble resistance to measurement according to worldly values can-like the inflexible nobility of tragic heroes-lead to collective calamity. Art lives in the world in order to disturb existing arrangements. And humanists who track the disturbance also have the capacity to project more of it, to imagine and to incite more art. Perhaps this is a moral imperative, since current arrangements can be cruel but seem natural.

The imperative drives Cultural Agents, an initiative that began at Harvard University fifteen years ago, when I started to feel desperate inside an academic culture that bred pessimism as sophistication. Where Adorno's ideological intransigence (against systems that would make us accomplices) and Foucault's discouraging spiral of repression and resistance pervaded the discourse, it was no wonder that disheartened students left the humanities to explore more useful fields. My response, along with that of many other beginners in the public humanities, was to revive a civic humanist tradition. By adding an "experimental" dimension to the humanities, Dimock's column suggests work yet to be done. It is the work of assessing impact.

However broad the definition of the "experimental method" in her reference to Rudolf Carnap (241), measurement and predictability are built into science. How else do we determine the success or failure of interventions? Surely rates of funding, which Dimock cites as evidence of success, matter. But these are perhaps responses to other numbers. It has been difficult for us, as humanists, to overcome a professional allergy to quantifiable evidence of effective interventions, but we can be cured. Therapy

(C) 2017 DORIS SOMMER

PMLA 132.5 (2017), published by the Modern Language Association of America 
began for me with Antanas Mockus, a former mayor of Bogotá, who reduced homicides by almost seventy percent while increasing tax revenues by three hundred percent during the city's desperate 1990s, through programs that included street arts. The numbers outdo in eloquence any other arguments for art. A lesson for experimental humanists is to intervene and to measure outcomes in order to scale up, to adjust, or to press the refresh button.

One Cultural Agents project inspired by Mockus and other Latin American educators, including Paulo Freire and Augusto Boal, is a teacher-training program called Pre-Texts. It turns any text into raw material for making art, so that new or reluctant readers feel authorized to have their way with even classical material, the way artists and intellectuals do. Since highorder literacy is a standard indicator in analyses of development (economic, political, psychosocial), humanists have an urgent contribution to make because they teach close reading. PreTexts is enormously successful, to judge from testimonies by teachers who encourage students to play with academic material and from students who warm up to reading, sometimes with the heat of resentment for conventional classes. But only consistent and large-scale measurement will make the magic scale up. Conventional testing misses the charm of close reading for irreverent users. It forgets to count pleasure among the conditions of learning (though neuroscience has for decades made the connection), and it treats citizenship as an area of development that is different from artistic collaboration. Better instruments for evaluation will support what we can do as public humanists.

Recently, Gonzalo invited me to initiate a collaboration in experimental humanities for the Instituto de Vivienda de la Ciudad de Buenos Aires (IVC), the city's housing authority. Since January 2017, he has added an area to his humanities agenda by heading up the cultural programs for a city institution that had not before considered culture a required dimension of urban development. But Juan Maquieyra, the director of IVC, knows that turning a slum into a neighborhood means creating social glue along with physical mortar, adding the pleasure of conviviality to imposed proximity. Impressed by Gonzalo's dedication to making good on theories of communication, society, and ethics, I offered to contribute a training workshop in Pre-Texts. For three days in August 2017, a heterogeneous group-academics, domestic workers, a grassroots drummer, a photographer, a psychologist, and a rookie teacher-convened in a storefront cultural center to train as PreTexts facilitators. Like stone soup, this approach works everywhere, gathering ingredients from local inhabitants to make something new and nourishing, collectively, with local resources.

We began, as always, by listening to a text read aloud (this time from Carl Sagan's Cosmos) while we did handicrafts and prepared a question-the way tobacco workers used to listen as they rolled cigars. Gonzalo was frankly surprised by the originality of the questions asked. Designed to level the playing field, since questions approach a text through ignorance and curiosity, the move showed that the heterogeneous group was the greatest gift to itself, a built-in refresh button that multiplied possible lines of inquiry and association. Reader-response theory was never more useful. Intertextuality, inevitable. In the next session, a domestic worker brought an article about innovations in astrophysics, and we explored the text with theater and dance. When we recognize everyone as an artist and pursue an interpretation the way scientists do, through trial and error, there are no losers, and admiration for one another is freely felt. Admiration-not tolerance-is the basic sentiment for citizenship, I learned from Mockus. The workshop does as much to raise the level of sociability as it does to raise the level of reading. Now our challenge, particular to Pre-Texts and general for the humanities, is to measure these advances in statistically eloquent ways to make good on our words as humanists. We claim to preserve and to extend the effects of art. We should do that.

Doris Sommer Harvard University 